John Carroll University

Carroll Collected

Institutional Effectiveness / Assessment

Fall 2018

\title{
Assessment in the Core: Centering Student Learning
}

Todd Bruce

John Carroll University, rbruce@jcu.edu

Follow this and additional works at: https://collected.jcu.edu/iea

Part of the Higher Education Commons

\section{Recommended Citation}

Bruce, Todd, "Assessment in the Core: Centering Student Learning" (2018). Institutional Effectiveness / Assessment. 1. https://collected.jcu.edu/iea/1

This Article is brought to you for free and open access by Carroll Collected. It has been accepted for inclusion in Institutional Effectiveness / Assessment by an authorized administrator of Carroll Collected. For more information, please contact connell@jcu.edu. 
John Carroll University engaged in a general education redesign with focused attention on assessment of student learning.

Widespread faculty involvement was key to a successful transition.

\title{
Assessment in the Core: Centering Student Learning
}

\author{
Robert Todd Bruce
}

John Carroll University is in the second year of implementing an ambitious visionary redesign of general education. The new integrative core curriculum replaced a traditional distributive curriculum with a new design with assessment in mind. The new core has strengthened the campus's nascent culture of assessment through widespread faculty involvement and engagement. This chapter describes the history of the new curriculum and how it differs from a traditional distributive model. Two key processes (an application for core designation and expectations for assessment of student learning) are described in detail, along with the results of the first round of assessment. The chapter concludes with some reflections about key components for success.

\section{Context and History}

John Carroll University (JCU) is a Jesuit Catholic university (one of twenty-eight in the United States), founded in 1886, and located in University Heights, Ohio, just outside of Cleveland. JCU offers undergraduate and graduate degrees to approximately 3000 students. The institution's mission is to inspire individuals to excel in learning, leadership, and service in the region and in the world. A Jesuit education serves not only to enrich the lives of graduates but also to challenge them to enrich the lives of others and to create a more just society. Historically, the institution has focused its curriculum on Ignatian pedagogy and supported faculty in their roles as scholar-teachers, believing that engaged researchers who invite students into their specialized areas of discovery offer an extraordinary learning experience, testified by strong retention rates and solid 4-year graduation rates.

In 2009, at the request of the faculty, the academic vice president convened a group of faculty from across the institution as the Academic 
Planning Task Force (APTF) and charged them to craft a document that would serve as a roadmap for the academic direction of the institution and to develop institutional academic student learning outcomes. Following a series of regular meetings throughout the year, the first draft of the desired document was produced at the Greater Expectations Institute sponsored by the Association of American Colleges \& Universities (AAC\&U). The final document included institutional learning outcomes and a vision statement for the entire curriculum, describing it as innovative, individual, integrated, and intentional.

In the second phase of the APTF project, the academic vice president assembled working groups to address the recommendations of the first APTF report. The curriculum working group found that the institution's existing core curriculum fell short of meeting the new learning outcomes faculty had adopted and began working on a new curriculum model, which went into effect for students matriculating in Fall 2015.

\section{Comparison of Old and New Core Curricula}

The university core curriculum, which had been in place for over a decade, represented a traditional distributive model. The curriculum assigned courses to divisions based on discipline and required students to choose from a menu of options for each division or requirement. The core's Division I required students to complete a three-credit first-year seminar, two semesters of English composition, a two-credit speech communication course, and two semesters of a foreign language. Division II required three courses: a literature course, a history (or art history) course, and one additional course selected from a menu of courses offered in English, history, art history, international cultures, foreign language, and communication. Division III required two courses selected from either economics, political science, or sociology/criminology. Division IV required students to select one mathematics course, one laboratory science (from biology, chemistry, or physics), and one additional course (from those four subjects plus psychology). Division V called for three philosophy courses and two religious studies courses. Three additional requirements, which could overlap with the divisional requirements, included a writing-intensive course, two international courses (one focusing on Asia, Africa, or Latin America), and a course focused on issues of diversity.

The new integrative core curriculum contains four key areas: foundational competency and language courses, integrated courses, Jesuit heritage courses, and requirements in the major. The new core identifies four foundational competencies: writing, speaking, quantitative analysis, and information/technological literacy. Students must complete three three-credit courses that focus on these skills: Seminar on Academic Writing (with required outcomes focusing on writing and information literacy), Speech Communication (with outcomes focusing on speaking and information 
literacy), and a course from the quantitative analysis category (with outcomes focusing on technological literacy, the ability to find, pose, and answer questions using quantitative methods). The integrated courses ask students to bring together knowledge, skills, and methodologies from different disciplines to explore important themes and issues. Integrated courses use a variety of teaching modalities to promote integration. Some courses are team-taught, some are offered by faculty who are members of a faculty learning community, and others are pairs of corequisite courses offered by faculty from different disciplines. Corequisite courses explore a common topic or theme and include shared experiences and assignments. The required outcomes of integrated courses focus on integration of the content of the two disciplines, writing and argument, critical analysis, and (in one category) understanding of global issues. The Jesuit heritage category requires students to complete two philosophy courses (one with an ethics component), two courses in theology or religious studies, a course focused on issues of social justice, and a course that requires participation in an artistic endeavor. Finally, each major must offer a course that teaches writing in a disciplinary context, and must provide students with both a disciplinarily appropriate oral presentation experience and a capstone experience.

The key difference between the university core and the integrative core is a switch from an input perspective to an outcomes perspective. In the university core, courses were assigned to divisions or requirements primarily based on the content or discipline of the course. Course designation was dependent solely on the inputs to the course (the instructor's departmental affiliation, the readings, the syllabus). As was typical for the institutional culture of the time, assessment of student learning was sporadic and limited. To qualify for a designation under the new core, faculty must show how their course will meet the outcomes required by that designation. Course designations now require an examination of the syllabus and assignments to determine if it is likely that students from the course will achieve the intended outcomes. At the same time, the new core has a comprehensive assessment plan, described in detail below, that was crafted alongside the implementation plan, rather than as an afterthought. The integrative core itself was designed specifically to meet specific outcomes, and the committee charged with its implementation has kept those outcomes centered in all discussions.

\section{Lead Up to Implementation}

Once the integrative core was adopted, a new committee was established to plan and oversee its implementation and operation. The core committee is made up of department chairs (or their designees) from the languages, philosophy, theology and religious studies, appointed positions (Director of First Year Writing, Director of Public Speaking, Director of Creative and Performing Arts), and elected positions (directors for each category in the 
integrated courses, social justice, and quantitative analysis). Each director chairs a three-person elected subcommittee to handle applications for and assessment of courses and learning outcomes that category. The core committee and the subcommittees provided leadership and transformed the core from a proposed vision to a reality. Shortly after its formation, the core committee added institutional assessment professionals as nonvoting advisory members.

The core committee ensured that assessment played a central role in the new core. Immediately after the core vote passed, a team of faculty attended an $A A C \& U$ workshop on assessing general education and drafted a pilot assessment framework for the new curriculum. The committee developed specific objectives for each of the nine academic student learning outcomes that the entire core was to deliver. These objectives served as the centerpiece of the assessment-focused application process implemented over the next 2 years. Course-development grants incentivized faculty to create new courses needed for the curriculum. Grant recipients were required to attend a workshop that discussed the role that assessment of student learning would play in the new core.

\section{Application Process}

For certain new core categories (Quantitative Analysis, linked courses, Engaging the Global Community team-taught or learning community courses, Issues in Social Justice, and Creative and Performing Arts), faculty complete an application for a particular course to receive a particular core designation. Each application requires a sample syllabus, a rationale describing why the designation is appropriate for the course, and, most importantly, a description of assignments that will allow the instructor to assess student learning outcomes in the course that aligned with the academic learning outcomes for that particular core category. Courses that cannot describe how learning will be assessed are not approved. However, the directors and subcommittees do work with applicants to ensure that the course and assignments are properly aligned with the intended outcomes for a resubmission. The Center for Teaching and Learning regularly co-sponsors workshops with the director of assessment to support faculty as they develop courses for the core and use evidence from assessment of student learning to improve pedagogy.

\section{Assessment Process}

The assessment process occurs in a number of phases involving instructors, the core committee, and the institutional assessment committee.

Instructor Assessment Work. Once a course has been taught, faculty members select at least one assignment that addresses each learning goal (a single assignment may address multiple goals). The faculty member 
then completes a rubric approved by the core committee and provides the scores as well as some record of the student's actual work to the core committee. Instructors can chose to complete the rubric as part of the grading process or as an independent assessment task. The submission of assessment data is automated for faculty using Canvas, the institution's learning management system. At the end of the semester, faculty who teach a course in a given category provide feedback to the core committee about the application and assessment processes.

Subcommittee Assessment Work. Each semester, each subcommittee invites those who have taught courses in that category to join them in their assessment work. Subcommittees (and any volunteers) norm the rubric using a small sample of student work from across courses. Each faculty member scores all of the assignments in the sample individually, using the rubric. They then meet to discuss their scores and resolve any differences, so that everyone gives work of similar quality a similar score. The subcommittees then score a larger sample of assignments. Some student work products are included in more than one subcommittee member's papers to enable subsequent checks for inter-rater reliability.

Subcommittee Assessment Meetings. Subcommittees schedule a half-day during the week between exams and commencement for an assessment meeting that is open to instructors who have taught in the category and any other interested parties. The group examines aggregated data from the instructors' and the subcommittees' assessment work and the feedback. They make recommendations for improvements to the process and to the curriculum itself (learning goals, recommended pedagogy, faculty development, policies, etc.). The discussion and recommendations are documented in a formal assessment report.

Core Committee Assessment Meeting. The entire core committee holds an open meeting to review the reports from the subcommittees (a half-day meeting scheduled during the same week as the subcommittee meetings). The core committee accepts, modifies, or rejects the subcommittee recommendations. Minutes for this meeting serve as the annual assessment report for the integrated core, which is available for faculty review and comment.

Institutional Assessment Committee Review. In the subsequent fall semester, the institutional assessment committee reviews all annual assessment reports and provides feedback and suggestions. The core committee then acts on the annual report and subsequent faculty input to potentially make changes to assessment processes and/or elements of the curriculum.

\section{Implementation}

The 2015-2016 academic year was the first year of implementation. The new core applied only to first-year students. All of the foundational 
competency, language, and philosophy and theology/religious studies categories offered a full slate of courses. Pilots of integrated, social justice, and arts courses were also offered. A solid percentage (67.5\%) of the sections offered reported assessment scores and/or provided student work in the first semester. As the newness of the process of submitting scores and work has worn off and faculty have become accustomed to using the Canvas technology, the reporting percentage increased to $74 \%$ in spring 2016 and $76.5 \%$ in Fall 2017. At the same time, the number of new core sections also increased (from just over 150 sections in Fall 2015 to around 300 in Spring 2017).

The foundational competency subcommittees reviewed student work samples for the first time in spring 2016 (for work sampled from courses offered in Fall 2015). Writing samples from the writing courses were reviewed and scored by both writing and information literacy reviewers. In 20162017, all subcommittees reviewed student work samples for their learning outcomes.

During the week between the conclusion of final exams and commencement, the core subcommittees met to review instructor-provided data from fall and spring (with the spring data being somewhat preliminary), subcommittee scores (where available), student work samples, and feedback from the survey of faculty that evaluated the application, approval, and assessment processes. These meetings were open to all faculty, with those who had taught in each category receiving an invitation; seven of the subcommittee meetings had at least one non-member attending.

Each subcommittee concluded its meeting by generating a report, responding to the following prompts:

- Describe, in words, what your subcommittee has learned about student learning during this assessment cycle (strengths? Weaknesses?)

- Do any of your findings translate into helpful suggestions for all instructors teaching courses with this designation?

- Describe, in words, your subcommittee's evaluation of application and assessment processes. What works well? What needs improvement? (All processes should provide useful data with a reasonable amount of effort.)

- What changes, if any, do you need to make to your application or assessment processes or to other aspects of your core designation that are within your control?

- What changes, if any, do you need to make to application or assessment processes or to other aspects of the core designation, including learning goals, rubrics, and curricular requirements and/or structures, that need full committee approval?

After the core committee had a day to review the reports, they convened for an open meeting to consider the findings and recommendations of the subcommittees and then engage in strategic planning (this discussion was open to committee members only). The final report from the first 
meeting (along with recommendations and feedback from the institutional assessment committee) served as the basis for the core committee's work during the following academic year.

\section{Changes Resulting from the Assessment Process}

One action by the core committee demonstrates how assessment can improve student learning. Members of the writing subcommittee, who reviewed student work from the Seminar on Academic Writing, were troubled by low scores on two particular objectives concerning students' ability to craft a written argument. The subcommittee decided to recommend a change to the common syllabus for the seminar, adding an argumentative writing assignment, which students submit before they complete the research paper used for core assessment. The core committee approved the change, and instructors discussed the committee's scores and the new syllabus at the fall first-year writing orientation session. Results from the next assessment cycle will evaluate the impact of this change.

Many changes focused on the revision of rubrics (clarification of language on writing rubric, standardization of number of levels of performance, reduction in number of dimensions of performance, common coding scheme). Institutional assessment committee feedback also guided the core committee to consider better ways to display and use assessment data (changes in progress) and to increase the use of sampling to reduce the burden on instructors (a process change still under discussion).

\section{Key Components of Success}

Faculty involvement improves when assessment activities are scheduled for time periods when faculty are on contract (unless supplemental funds are available for stipends). Schedule assessment activities at times when faculty workload is less frantic. At JCU, the week in the spring between the conclusion of exams and commencement ceremonies is perfect for assessment work.

The new core is far from perfect. Each semester adjustments have been made to make implementation more manageable. Initially, some categories were assigned far too many learning outcomes, so based on instructor feedback, the committee removed some outcomes. As another example, rubrics have been modified to improve clarity and consistency of use. Future changes are inevitable. However, JCU's experience shows it is possible to undertake substantial core reform and place assessment of student learning at the heart of the reform. The success to this point may be even more surprising when one considers that the integrative core came into being during a time of transition at the institution: there have been a number of changes in senior leadership since the inception of the first academic planning task force, and the higher education market in our area has 
become even more competitive and challenging. At the time of the creation of the core, assessment was not consistently in place across campus, but the core implementation was benefited by accreditation-related efforts, which spurred an institutional culture shift when it comes to assessment.

Several institutional commitments were critical to the new core's successful implementation. Although the director of assessment, a staff position, was created to assist with accreditation issues, an important additional function of the position is to advise the core committee on assessment issues and assist core instructors and subcommittees in completing their assessment tasks. This assistance ranged from syllabus and assignment consultations to technical support with Canvas. The director of the Center for Teaching and Learning crafted programming for professional development that helped faculty make the transition to the new core. However, a key element for successful implementation was widespread faculty involvement in core planning, implementation, and assessment. It is difficult to argue that something has been imposed by administrators when faculty members are the ones making the key decisions, setting the criteria, building the processes, and providing feedback. Finally, the process created a positive feedback loop: as the institutional assessment culture grows, core assessment becomes easier, more familiar, and eventually more helpful. At the same time, widespread involvement in core assessment strengthens and builds the culture of assessment. Prior to the new core's implementation, assessment processes in departments and the university core were sporadic, inconsistent, and poorly documented. Assessment knowledge and expertise resided in a few faculty and administrators. Two years into the implementation of the new core, JCU is a very different place: Faculty involvement in assessment is widespread and many now see it as means to ensure and improve student learning across campus.

ROBERT TODD BRUCE is the director of academic assessment and a member of the office of institutional effectiveness at John Carroll University. 